\title{
1 Solution Structure of an "open” E. coli Pol III Clamp \\ 2 Loader Sliding Clamp Complex
}

\author{
3 Farzaneh Tondnevis ${ }^{a}$, Thomas M. Weiss ${ }^{b}$, Tsutomu Matsui ${ }^{b}$, Linda B. Bloom ${ }^{a}$ and \\ 4 Robert Mckenna ${ }^{a^{*}}$ \\ $5{ }^{a}$ Biochemistry and Molecular Biology, University of Florida, PO BOX 100245, Gainesville, \\ 6 Florida, 32610, United States \\ 7 bStanford Synchrotron Radiation Lightsource, 2575 Sand Hill Road, MS69, Menlo Park, CA \\ 8 94025, United States \\ $9{ }^{*}$ Correspondence: rmckenna@ufl.edu

\section{ABSTRACT}

Sliding clamps are opened and loaded onto primer template junctions by clamp loaders, and once loaded on DNA, confer processivity to replicative polymerases. Previously determined crystal structures of eukaryotic and T4 clamp loader-clamp complexes have captured the sliding clamps in either closed or only partially open interface conformations. In these solution structure studies, we have captured for the first time the clamp loader-sliding clamp complex from Escherichia coli using size exclusion chromatography coupled to small angle X-ray scattering (SEC-SAXS). The data suggests the sliding clamp is in an open conformation which is wide enough to permit duplex DNA binding. The data also provides information about spatial arrangement of the sliding clamp with respect to the clamp loader subunits and is compared to complex crystal structures determined from other organisms. 


\section{Introduction}

During DNA synthesis and replication the daughter strands are copied at a fast rate and in an accurate manner by DNA polymerases (Benkovic et al., 2001; Kong et al., 1992; Onrust et al., 1991; Pomerantz and O'Donnell, 2007; Stukenberg et al., 1991). The accuracy is an inherent property of DNA polymerases but the processivity (up to 1000 nts in a single binding event) is conferred through binding with sliding clamps (Shamoo and Steitz, 1999; Kong et al., 1992; Onrust et al., 1991; Stukenberg et al., 1991). The sliding clamps anchor and topologically link the polymerases to the DNA and prevent premature dissociation. A sliding clamp is loaded onto the primer template junction on the DNA lagging strand every 2-3 seconds in E. coli (Wu et al., 1992, Moolman et al., 2014).

Because of the inherent closed ring nature of the majority of uncomplexed sliding clamps, a multi-subunit macromolecule referred to as clamp loader is required for loading of the clamp. Clamp loaders are members of family of ATPase associated with various cellular activities (AAA+) which use ATP binding and hydrolysis to bind, open and load sliding clamps in the correct orientation onto primer template junctions (Erzberger and Berger, 2006; Neuwald et al., 1999). In contrast to other members of AAA+ family of ATPases, clamp loaders are heteropentameric. The absence of a sixth subunit provides a gap for binding of DNA/RNA primer template substrates (Bowman et al., 2004; Simonetta et al., 2009). ATP binding increases the affinity of the clamp loader for binding the sliding clamp through induction of conformational changes. These conformational changes are necessary for interaction of the loader with the clamp as well as with the primer template DNA (Bowman et al., 2004; Jeruzalmi et al., 2001b; 
49 Simonetta et al., 2009; Hingorani and O'Donnell, 1998). Once the sliding clamp is 50 loaded onto the DNA, the clamp loader releases and closes the sliding clamp around

51 the DNA. These steps are coupled to ATP hydrolysis and dissociation of ADP from the 52 clamp loader (Jarvis et al., 1989; Turner et al., 1999). Once the sliding clamp is 53 released the polymerase binds the clamp and carries out DNA replication.

54 Previously, the X-ray crystal structure of the eukaryotic pentameric clamp loader, 55 replication factor $\mathrm{C}$ (RFC), bound to a closed homotrimeric sliding clamp referred to as 56 proliferating cellular nuclear antigen (PCNA) from Saccharomyces cerevisiae has been 57 determined (Bowman et al., 2004). Because ATP hydrolysis weakens the interaction of 58 sliding clamp and the clamp loader, a variant of the clamp loader complex (where the arginine finger of the SRC motifs in RFC-B, RFC-C, RFC-D and RFC-E subunits were 60 mutated to glutamine) was used which resulted in the capture of the clamp loader-clamp 61 structure, but the PCNA clamp was in a closed conformation. The crystal structure 62 revealed a spiral arrangement of ATPase domains of clamp loader with the N-terminal 63 domains of the subunits interacting with the PCNA ring and DNA modeled within the 64 central hole of the PCNA and primer template binding channel of RFC also revealed 65 that the RFC spiral complemented the grooves of the modeled duplex DNA. This crystal 66 structure presented the "screw cap" interaction of RFC with primer template DNA.

67 Further understanding of the mechanism of clamp loading reaction has been gained 68 from the crystal structure of an ATP bound state of the bacteriophage T4 clamp loader 69 bound to the gp45 sliding clamp and primer-template DNA (Kelch et al., 2011). Previous 70 studies on the T4 sliding clamp has shown the clamp having an open conformation in 71 solution in the absence of the loader (Alley et al., 1999; Millar et al., 2004). However, 
72 the X-ray crystal structure of the T4 clamp loader-clamp-DNA complex revealed a

73 partially opened sliding clamp. The opening at the clamp interface was approximately

$7410 \AA$, not wide enough to thread duplex DNA. The spiral conformation of the clamp

75 matched the spiral of the primer-template DNA as well as the clamp loader. This

76 structure also revealed extensive interactions between all the five subunits $\mathrm{N}$-terminal

77 domains of the clamp loader with the bacteriophage gp45 sliding clamp.

In E. coli, the sliding clamp is referred to as the $\beta$ sliding clamp and the clamp loader complex as either the $\gamma$ or $\tau$ complex. The crystal structure of the $\beta$ sliding clamp revealed the molecule to be a homodimer (with an outer and inner diameter of 80 and $40 \AA$, respectively). Each of the monomers (comprised of 366 residues) with head to tail interaction arrangement, that results in the $\beta$ sliding clamp having two distinct faces (Kong et al., 1992). The $\beta$ sliding clamp interacts with several protein partners during DNA replication and repair using one of these faces (which has several surface protruding loops). Although the X-ray crystal structure of the clamp was of a closed ring, solution studies of the clamp using hydrogen exchange mass spectroscopy have revealed that $\beta$ clamp is not a static closed ring in solution but highly flexible (Fang et al., 2011). The same studies also suggested that intermediate conformations of the clamp might facilitate interactions with different protein partners.

The E. coli clamp loader complex is a multi-subunit macromolecule comprised of the seven subunits $\delta, \delta^{\prime}, \psi$ and $\chi$ and three protomers of the dnaX gene products (either $\gamma$ or $\tau)$. It was demonstrated that the clamp loader with any combination of $\gamma$ or $\tau$ subunits $\left(\gamma_{2} \tau, \gamma \tau_{2}, \gamma_{3}\right.$ or $\left.\tau_{3}\right)$ were equally active in loading the clamp onto DNA (Mclnerney et al., 2007). Several X-ray crystal structures of the $\gamma$ clamp loader have been determined but 
the $\chi \psi$ subunits, which are required for bridging the interaction of single stranded DNA binding protein (SSB) with the clamp loader, were absent (Jeruzalmi et al., 2001b; Kazmirski et al., 2004; Simonetta et al., 2009). The omission of $\chi \psi$ subunits was because of the inherent flexibility of the $\psi$ subunit $27 \mathrm{~N}$-terminal residues that anchor the $\chi \psi$ heterodimer to the core five subunit (Glover and McHenry, 1998). The $\psi$ subunit interacts with the C-terminal region of $\gamma$ subunit (Gao and McHenry 2001). These two subunits together are essential for bridging the interaction between the clamp loader and SSB in E. coli (Glover and McHenry 1998). The $\psi$ subunit plays a role in stabilizing the conformational changes induced by ATP binding and the $\chi$ subunit directly interacts with the $\mathrm{C}$ terminus of SSB (8 amino acid residues). The $\chi \psi$ complex also plays a role in increasing the affinity of $\tau$ and $\gamma$ for $\delta . \delta$ ' to a physiologically relevant range and stabilization of the complex (Olson et al., 1995). In a recent study on the solution structure of the $\gamma$ clamp loader, the location of $\chi \psi$ was revealed (Tondnevis et al., 2015). The $\chi \psi$ heterodimer interacts with the C-terminal collar region of the loader and was positioned opposite of the ssDNA exit channel on $\delta$ subunit and closer to $\delta$ '.

To date there is no X-ray crystal or cryo-electron microscopy (cryo-EM) structure of any clamp loader-clamp complex in which the sliding clamp has been shown to be open wide enough at the interface for the binding of duplex DNA. In these studies, we have captured a solution structure of the $E$. coli $\beta$ sliding clamp loader-clamp complex using small angle X-ray scattering coupled to size exclusion chromatography (SEC-SAXS). Rigid body modeling of the clamp loader-clamp to fit the 1D-scattering data shows the topological arrangement of the $\beta$ sliding clamp with respect to the $\gamma$ clamp loader. The clamp makes interactions with the $\mathrm{N}$-terminal domains of all the core subunits. This 
118 arrangement is similar to that seen in the RFC-PCNA crystal structure, bacteriophage

119 T4 clamp loader-clamp-DNA complex structure and the archaeal Pyrococcus furiosus

$120(P f u)$ clamp loader-clamp-DNA ternary structure previously determined using X-ray 121 crystallography and cryo-EM (Bowman et al., 2004, Kelch et al., 2011, Miyata et al., 122 2005). Our model also suggests that the clamp exists in an open conformation in 123 complex with the clamp loader and has an out of plane opening wide enough $(\sim 25 \AA)$ 124 for the binding of duplex DNA.

\section{2. Materials and methods}

\section{Protein preparation and purification}

127 E. coli $\beta$ sliding clamp was purified as described previously with minor modifications 128 (Anderson et al., 2009; Johanson et al., 1986). The stock concentration for $\beta$ sliding 129 clamp was $90 \mu \mathrm{M}(7.4 \mathrm{mg} / \mathrm{ml})$ for the dimer. The protein was $>95 \%$ pure as measured by SDS-PAGE gel. The storage buffer was $20 \mathrm{mM}$ Tris- $\mathrm{HCl}$ at $\mathrm{pH}$ 7.5, $0.5 \mathrm{mM}$ EDTA, 5

132 were transformed with pCOLADuet-1 and pETDuet-1 vectors. The plasmids were 133 generous gifts from Linda Bloom \& Lauren Douma (University of Florida. Department of 134 Biochemistry and Molecular Biology). The pCOLADuet-1 vector contained the coding 135 sequence for $\delta$ subunit as well as $\gamma$ subunit and the pETDuet-1 vector contained the coding sequence for the $\delta$ ' as well as $\psi \chi$ subunits ( $\psi$ and $\chi$ were part of a single operon).

137 Transformation colonies were used to grow $20 \mathrm{ml}$ of starter culture containing ampicillin 138 and kanamycin as selective markers. The starter culture was grown to optimum density 139 and centrifuged and the pellet was re-suspended in fresh media. For large-scale 140 expression of the $\gamma$ clamp loader, 2L of LB media supplemented with ampicillin and 
141 kanamycin $(100 \mu \mathrm{g} / \mathrm{ml}$ and $50 \mu \mathrm{g} / \mathrm{ml})$ was inoculated with $E$. coli starter culture. The

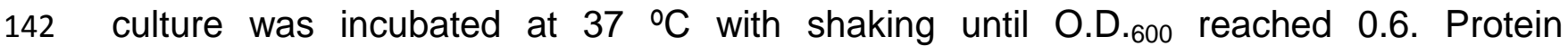
143 expression was induced using IPTG to a final concentration of $1 \mathrm{mM}$ followed by an 144 additional 3-hour incubation of the culture at $37^{\circ} \mathrm{C}$ with shaking. The culture was then 145 centrifuged at $5000 \times \mathrm{g}$ at $4{ }^{\circ} \mathrm{C}$ for 30 minutes. Pellets were then frozen at $-80{ }^{\circ} \mathrm{C}$.

146 For purification of $\gamma$ clamp loader, thawed frozen pellets were re-suspended in re147 suspension buffer containing $20 \mathrm{mM}$ Tris- $\mathrm{HCl}$ at pH 7.5, $0.5 \mathrm{mM}$ EDTA, $2 \mathrm{mM}$ DTT, 50 $148 \mathrm{mM} \mathrm{NaCl}$ and $10 \%$ glycerol by stirring. Cells were lysed using French pressure cell. 149 Cells were passed through the French press 3 times on high pressure (1000 psi). Lysed 150 cells were then centrifuges at 18000 RFC using a JA 20 rotor (Beckman) at $4{ }^{\circ} \mathrm{C}$ for 1 151 hour. The cleared lysate was collected and loaded onto a regenerated 2x5 ml HiTrap 152 Heparin column (GE Healthcare). The unbound proteins were washed away using the 153 loading buffer (same as re-suspension) until the UV absorbance was stabilized. The 154 protein was eluted using a linear gradient $(50-1000 \mathrm{mM} \mathrm{NaCl})$. The fractions containing 155 clamp loader were pooled and dialyzed against $2 \mathrm{~L}$ of dialysis buffer, which contained 20 $156 \mathrm{mM}$ Tris- $\mathrm{HCl}$ at $\mathrm{pH}$ 7.5, $0.5 \mathrm{mM}$ EDTA, 2mM DTT, $100 \mathrm{mM} \mathrm{NaCl}$ and $10 \%$ glycerol. For 157 purifying the protein further, the dialyzed protein was loaded onto a regenerated $8 \mathrm{ml}$ 158 Mono Q column (Pharmacia). The unbound proteins were washed away using $40 \mathrm{ml}$ of 159 loading buffer (same as dialysis buffer). The clamp loader was eluted using a linear 160 gradient (100-1000 mM NaCl). Clamp loader eluted around $450 \mathrm{mM} \mathrm{NaCl}$. The peak 161 fractions were ran on a $12 \%$ SDS-PAGE gel and the fractions containing pure clamp 162 loader were pooled and dialyzed into storage buffer containing $20 \mathrm{mM}$ Tris- $\mathrm{HCl}, 50 \mathrm{mM}$ $163 \mathrm{NaCl}, 2 \mathrm{mM}$ DTT and $10 \%$ glycerol. Concentrations of $\gamma$ complex was determined by 
164 measuring the absorbance at $280 \mathrm{~nm}$ in $6 \mathrm{M}$ guanidine hydrochloride and using the 165 calculated extinction coefficient $\left(220,050 \mathrm{~m}^{-1} \mathrm{~cm}^{-1}\right)$ (Gill and von Hippel 1989). The 166 sliding clamp concentration was determined using Bradford assay with beta dilutions as 167 standards instead of bovin serum albumin (BSA).

\section{Small angle X-ray scattering data collection}

For the solution structural characterization of the $\beta$ sliding clamp, $100 \mu \mathrm{l}$ of sample (7.4

$170 \mathrm{mg} / \mathrm{ml}$ ) was loaded onto a $2.4 \mathrm{ml}$ Superdex 200 PC3.2 size exclusion column through

171 use of sample loop. The column had previously been equilibrated with 5 column 172 volumes $(\mathrm{CV})$ of running buffer containing $20 \mathrm{mM}$ Tris- $\mathrm{HCl}$ at $\mathrm{pH} 7.5,0.5 \mathrm{mM}$ EDTA, 5 $173 \mathrm{mM}$ DTT and $4 \%$ glycerol. For SAXS analysis of the $\gamma$ clamp, the column was 174 regenerated using $5 \mathrm{CV}$ of buffer containing $20 \mathrm{mM}$ Tris- $\mathrm{HCl}$ at $\mathrm{pH} 7.5,0.5 \mathrm{mM}$ EDTA, $1754 \%$ glycerol, $5 \mathrm{mM}$ DTT, $100 \mathrm{mM} \mathrm{NaCl}, 500 \mathrm{uM}$ ATP and $8 \mathrm{mM} \mathrm{MgCl}$. The clamp 176 loader was mixed with ATP (final concentration of $500 \mu \mathrm{M}$ ) and $100 \mu \mathrm{l}$ of sample (11 $177 \mathrm{mg} / \mathrm{ml}$ ) was loaded onto the column using the sample loop. For obtaining a structure of 178 the clamp loader-clamp complex the two proteins were mixed using a 1:1 molar ratio to 179 the final concentration of $30 \mu \mathrm{M}$. The column was regenerated and run in a buffer 180 containing $20 \mathrm{mM}$ Tris- $\mathrm{HCl}$ at $\mathrm{pH}$ 7.5, $0.5 \mathrm{mM}$ EDTA, 4\% glycerol, $5 \mathrm{mM}$ DTT, $200 \mathrm{mM}$ $181 \mathrm{NaCl}, 500$ uM ATP, $8 \mathrm{mM} \mathrm{MgCl}$. All running buffers were degassed prior to column 182 regeneration.

183 SAXS data was collected at the Bio-SAXS beam line BL4-2 at Stanford Synchrotron 184 Radiation Lightsource (SSRL) (Smolsky et al., 2007). The beam size at the sample was 185 defined to be $250 \mu \mathrm{m} \times 300 \mu \mathrm{m}$ (vertical $\times$ horizontal) resulting in a total photon flux of 186 approximately $1 \times 10^{12}$ photons/s. All data were collected using a Rayonix MX225-HE 
187 CCD detector (Rayonix, Evanston, IL) with a $2.4 \mathrm{~m}$ sample-to-detector distance and a beam energy of $11 \mathrm{keV}$ (wavelength, $\lambda=1.127 \AA$ ). Scattering data were collected within a q range of $0.005 \AA^{-1}<q<0.4 \AA^{-1}$, where $q=4 \pi \sin (\theta) / \lambda$ is the momentum transfer and $2 \theta$ the scattering angle. The q scale was calibrated using the powder diffraction of silver behenate (Huang et al., 1993). For the SEC-SAXS experiment an AKTA Ettan FPLC 192 (GE-Healthcare) was used. Solution eluting from the size exclusion column was 193 redirected to the sample flow path for immediate SAXS data collection. Samples (50$194100 \mu \mathrm{l}$ ) were loaded onto a $2.4 \mathrm{ml}$ Superdex 200 PC 3.2 size exclusion column and run 195 at a flow rate $0.05 \mathrm{ml} / \mathrm{min}$. The first 100 images were scaled and averaged to create a 196 buffer-scattering profile, and this was then subtracted from each of the subsequent 197 images to produce the final scattering curve for each exposure. The exposure time was 1981 second with a $2.5 \mathrm{~s}$ delay between each exposure. For each individual sample the 199 scattering profiles over the elution peak were averaged and used for further analysis. 200 The data acquisition program Blu-ICE (McPhillips et al., 2002) was employed for data 201 collection. Program SASTOOL was used for data reduction, scaling and integration of 202 scattering images after inspection for any variations potentially caused by radiation 203 damage.

\section{Software and modeling of SAXS data}

205 The first 100 data frames collected during the SEC run were averaged and used as the 206 buffer background for the subsequent scattering profiles of that run. The buffer 207 subtracted data were then averaged in groups of five for improved statistics. For further 208 analysis, data were chosen within the region of constant $R_{g}$ values. The analyzed 209 frames for $\gamma$ clamp loader, $\beta$ sliding clamp and $\gamma$ - $\beta$ clamp loader-clamp complex are 
210 highlighted in supplemental figures (Figures S1, S2 and S3). The ATSAS suite of 211 programs (version 2.5.2) from EMBL (European Molecular Biology Laboratory) in 212 Hamburg was used for data processing. PRIMUS (Konarev et al., 2003) from the 213 ATSAS suite was used to calculate the Guinier plots for calculation of zero angle

Table 1. Data-collection and scattering-derived parameters for SEC-SAXS

\begin{tabular}{|c|c|c|c|}
\hline & $\gamma$ clamp loader & $\beta$ sliding clamp & $\beta-\gamma$ complex \\
\hline \multicolumn{4}{|l|}{ Data-collection parameters } \\
\hline Instrument ${ }^{*}$ & \multicolumn{3}{|l|}{ SSRL BL4-2 } \\
\hline Beam geometry* & \multicolumn{3}{|c|}{$250 \mu \mathrm{m} \times 300 \mu \mathrm{m}$} \\
\hline Detector Distance $(\mathrm{m})^{*}$ & \multicolumn{3}{|l|}{2.4} \\
\hline Wavelength $(\AA)^{*}$ & \multicolumn{3}{|l|}{1.127} \\
\hline Energy $(\mathrm{keV})^{*}$ & \multicolumn{3}{|l|}{11.0} \\
\hline q range $\left(\AA^{-1}\right)^{*}$ & \multicolumn{3}{|l|}{$0.005-0.4$} \\
\hline Exposure time per frame $(\mathrm{s})^{*}$ & \multirow{2}{*}{\multicolumn{3}{|c|}{$\begin{array}{l}1.0 \\
293\end{array}$}} \\
\hline Temperature $(\mathrm{K})^{*}$ & & & \\
\hline \multicolumn{4}{|l|}{ SEC specifications } \\
\hline Flow speed $(\mathrm{ml} / \mathrm{min})^{*}$ & \multicolumn{3}{|l|}{0.05} \\
\hline Concentration $(\mathrm{mg} / \mathrm{ml})$ & \multirow{2}{*}{\multicolumn{2}{|c|}{$\begin{array}{r}12.0 \\
100.0\end{array}$}} & 5.0 \\
\hline Volume loaded $(\mu \mathrm{l})$ & & 100.0 & 50.0 \\
\hline \multicolumn{4}{|l|}{ Structural parameters } \\
\hline$R_{g}(\AA)[$ from $P(r)]$ & \multirow{2}{*}{$\begin{array}{l}52.9 \pm 0.2 \\
51.6 \pm 0.1\end{array}$} & \multirow{2}{*}{$\begin{array}{l}33.2 \pm 0.2 \\
32.5 \pm 0.1 \\
33.9\end{array}$} & \multirow{2}{*}{$\begin{array}{l}53.8 \pm 0.2 \\
53.1 \pm 0.2\end{array}$} \\
\hline $\begin{array}{l}\mathrm{R}_{\mathrm{g}}(\AA) \text { [from Guinier] } \\
\mathrm{R}_{\mathrm{a}}(\AA) \text { [from PDB] }\end{array}$ & & & \\
\hline$D_{\max }(\AA)$ [ from $\left.P(r)\right]$ & \multirow{2}{*}{$\begin{array}{r}200.0 \\
90.0\end{array}$} & \multirow[t]{2}{*}{95.0} & \multirow[t]{2}{*}{205.0} \\
\hline $\mathrm{D}_{\max }(\mathrm{A})[\text { from } \mathrm{PDB}]^{1}$ & & & \\
\hline MW (using the amino acid sequence) & ce) 250.0 & \multirow{2}{*}{$\begin{array}{l}80.0 \\
79.8\end{array}$} & \multirow{2}{*}{$\begin{array}{l}330.0 \\
328.8\end{array}$} \\
\hline MW (kDa) (using Porod Volume) ${ }^{2}$ & 305.0 & & \\
\hline \multicolumn{4}{|l|}{ Software employed } \\
\hline Primary data collection* & \multicolumn{2}{|l|}{ Blue-ICE } & \\
\hline Data scaling, averaging ${ }^{*}$ & \multirow{2}{*}{\multicolumn{2}{|c|}{ SASTOOL }} & \\
\hline Rigid-body modeling* & & & \\
\hline Computation of model intensities* & & \\
\hline 3D graphics representation ${ }^{*}$ & \multicolumn{2}{|c|}{$\begin{array}{l}\text { CRYSOL } \\
\text { CHIMERA, PYMOL }\end{array}$} & \\
\hline
\end{tabular}
distance distribution $\mathrm{P}(\mathrm{r})$ function (Svergun, 1992). The program COOT (Emsley and 
249 Cowtan, 2004) was used for creation of structural models. The models were later used

250 for generation of calculated SAXS profiles. Chimera (Pettersen et al., 2004) and Pymol

251 molecular visualization programs (The PyMOL Molecular Graphics System, Version

252 1.7.4 Schrödinger, LLC) were used for graphical presentation of structural models.

253 CRYSOL was used for generation of calculate scattering profiles (Svergun et al., 1995).

\section{3. Results}

255 An initial size exclusion chromatography coupled to small angle X-ray scattering (SEC256 SAXS) of the individual E. coli $\gamma$ clamp loader and $\beta$ sliding clamp were determined as 257 baseline measurements to check that both the samples were monodispersed and to 258 obtained the structures of their unbound states so as to compare with the $\gamma-\beta$ complex 259 form. Although both the clamp loader and sliding clamp are stable, the use of SEC260 SAXS for data collection was to ensure the removal of all possible aggregates that have 261 been known to exist from off-line size exclusion purification of the clamp loader. The 262 data collection and scattering derived parameters are summarized in Table 1.

$263 \gamma$ Clamp loader

264 The $\gamma$ clamp loader data acquisition used $100 \mu \mathrm{l}$ of protein at a concentration of 11 $265 \mathrm{mg} / \mathrm{ml}$. The in-line size exclusion UV chromatogram is shown in Figure S1A and shows 266 the separation of a minor fraction of aggregates (relative height of the peak) before the 267 major peak fraction corresponding to the monodisperse sample. The SAXS parameter 268 radius of gyration $\left(R_{g}\right)$ and forward scattering intensity $(I(0))$ and the $I\left(q_{\min }\right)$, which is the 269 intensity at minimum angle measured, of each exposure frame are shown in Figure 270 S1B. The frames at the trailing edge of the major peak that were not influenced by the 
presence of large aggregates were used for averaging and determination of SAXS parameters. These frames exhibited constant $R_{g}$ values, indicating monodispersity as well as the absence of intermolecular interaction. The averaged and buffer subtracted

274 1D scattering curve for the $\gamma$ clamp loader is shown (Figure 1A). The Guinier plot of the 275 data exhibits excellent linearity in the low q region with a resulting radius of gyration of
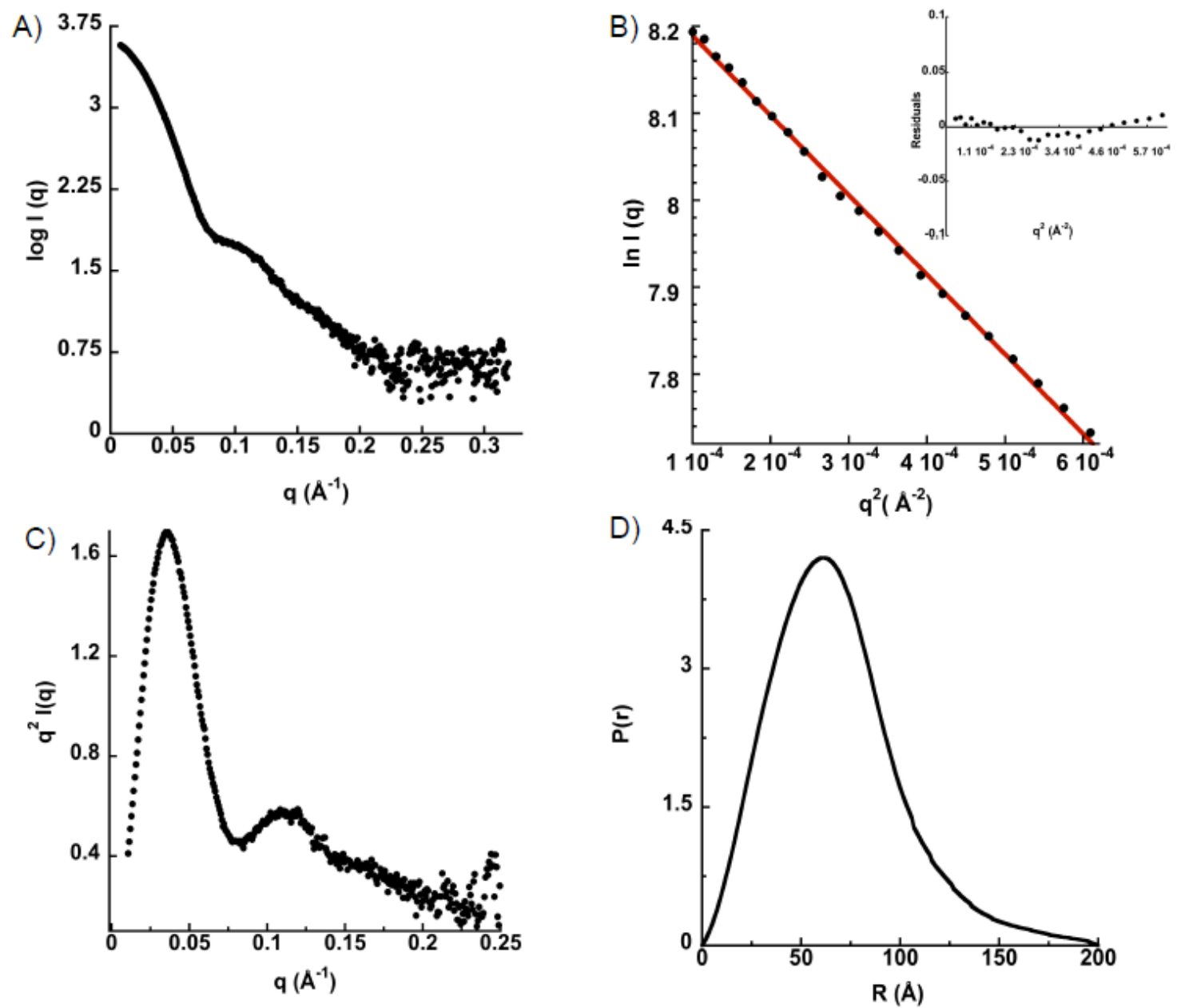

Figure 1: SEC-SAXS of the seven subunit $\gamma$-clamp loader. A) Buffer subtracted 1D scattering curve. Shown are the average of frames 360-375 as highlighted in Figure S1. B) Guinier analysis. The $R^{2}$ value for the line was 0.998 and the residual linear fit in $R_{g} . q$ $<1.3$ region is shown as an inset. C) Kratky plot. The plot has a bell shape peak at low momentum transfer (low q) expected of globular macromolecules. D) The pair wise distance distribution function $p(r)$. The bell shape function is expected of a protein that is mostly spherical. The $D_{\max }$ was $200 \AA$. 
$28551.2 \pm 0.2 \AA$ (Figure 1B). The Kratky plot exhibits a bell shaped peak at low momentum 286 transfer values and converges to the $\mathrm{x}$-axis at higher $\mathrm{q}$ values characteristic of a 287 globular and well-folded protein (Rambo and Tainer, 2011) (Figure 1C). The $p(r)$ 288 function reveals that $\gamma$ clamp loader is mostly spherical in shape with an extended 289 domain corresponding to the extended $\chi \psi$ subunits (Figure 1D). The maximum $\left(D_{\max }\right)$ 290 was calculated to be $200 \AA$ slightly larger than $190 \AA$ calculated from our rigid-body 291 model of the seven-subunit loader. For calculation of the $D_{\max }$ value for the seven 292 subunit clamp loader, the coordinates of the $\chi \psi$ subunits (PDB: 1EM8) (Gulbis et al., 293 2004) were manually docked with the five subunit $\gamma$ clamp loader (PDB: 3GLI) 294 (Simonetta et al., 2009) using the program COOT (Emsley and Cowtan, 2004) in 295 accordance to the recently determined SAXS ab initio 3D model of the seven subunit 296 clamp loader complex (Tondnevis et al., 2015) (Figure 2B).

297 For modeling of the SAXS data, program CRYSOL was used to compare the 298 experimental scattering data to the structural models of the $\gamma$ clamp loader (Svergun et 299 al., 1995). Theoretical scattering curves were generated for two structural models 300 (Figure 2). For a given data set one can use $\chi$ value to rank different structural models in 301 which case the lower value represents the better model. Acceptable $\chi$ values are 302 typically somewhere close to unity. However the absolute value of $\chi$ is not a very useful 303 number as the value depends on the noise in each of the data points and for a noisy 304 data larger values can be acceptable. It should be noted that in principle it is not 305 possible to use the absolute $\chi$ value to compare the quality of different models to 306 different data sets. 
The first model used the coordinates (PDB ID: $3 G \mathrm{GL})$ for the five-subunit $\left(\gamma_{3} \delta \delta^{\prime}\right)$ clamp loader with removal of the DNA and $\psi$ peptide (Simonetta et al., 2009). This structure was determined in the presence of the $\psi$ peptide, where the peptide was interacting with
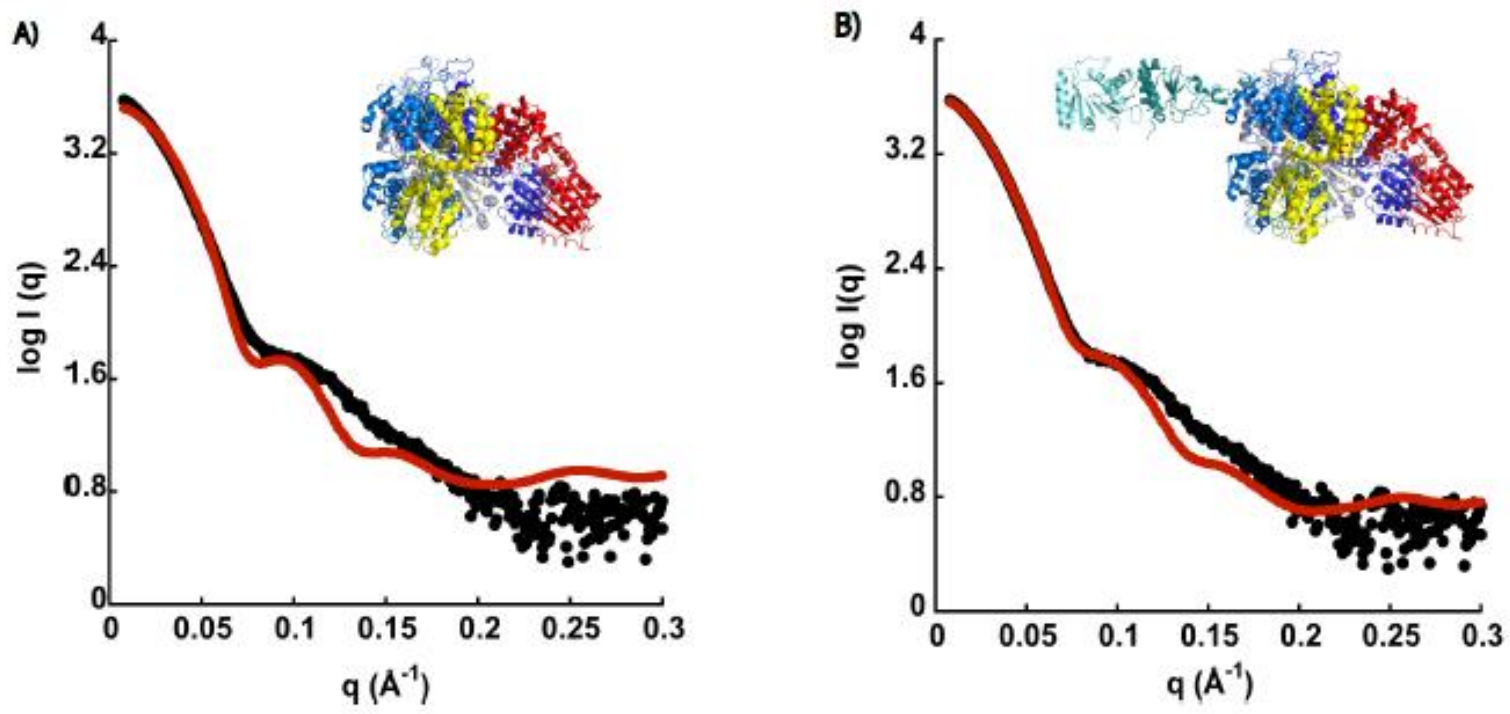

Figure 2: Modeling of the $\gamma$-clamp loader. The program CRYSOL was used for generating 1D scattering profile of atomic models shown in each panel. The subunits of the atomic models of the clamp loader in panels A and B are color coded as followed: $\delta$ ' yellow, $3 \gamma$ subunits in shades of blue, $\delta$ red. The $\chi \psi$ subunits in panel $B$ are shown in cyan and deep teal, respectively. The black curves in panel $A$ and $B$ are the experimental SAXS data and the red curves are the calculated scattering curves for the atomic models in each panel. A) Fitting of calculated scattering profile for the $\delta, \delta, 3 \gamma$ clamp loader to the experimental data. B) Fitting of the calculated scattering profile for the seven subunit clamp loader complex with $\chi \psi$ subunits positioned close to $\delta$ ' based on previous ab initio model of the clamp loader.

321 the C-terminal collar region of the $\gamma$ subunits. The second structural model used was the seven-subunit complex $\left(\gamma_{3} \delta \delta^{\prime} \psi \chi\right)$ described in Tondnevis et al., 2015 (PDB: 1EM8 for $\psi \chi$ subunits, Gulbis et al., 2004)). In figure 2, the red curves are calculated using the two models and the black curves are the experimental data. When the calculated scattering profile for the five-subunit complex was compared to the data, the $\chi$ value was 7.2 and calculated $R_{g}$ value was $42.5 \AA$ as compared to experimental value of $51.2 \pm 0.2 \AA$ 
327 (Figure 2A). Whereas, the scattering profile calculated for the seven-subunit complex 328 (Tondnevis et al., 2015) was a better fit to the 1D scattering data. The $\chi$ value was 329 decreased to 2.4 and there was a close agreement between theoretical $R_{g}$ value of 51.3 330 and experimental value of $51.2 \pm 0.2 \AA$ (Figure $2 \mathrm{~B}$ ). It should be noted that the fit of the 331 structural model to the experimental data in figure $2 \mathrm{~B}$ is not unique. The proposed 332 model is overall consistent with the data but there are some discrepancies between the 333 calculated curve based on the presented model and the data at higher $q$ values. This 334 discrepancy can be explained by possible intra and inter domain movements of the 335 clamp loader subunits in solution.

\section{$\beta$ sliding clamp}

337 For $\beta$ sliding clamp data acquisition $100 \mu \mathrm{l}$ of sample at a concentration of $7.2 \mathrm{mg} / \mathrm{ml}$ was used. The in-line size exclusion UV chromatogram is shown (Figure S2A). The 339 SAXS parameters radius of gyration $\left(R_{g}\right)$, forward scattering intensity $(I(0))$, the 340 minimum intensity value $\left(I\left(q_{\min }\right)\right)$ of each exposure frame, and the images chosen for 341 averaging and analysis for determination of SAXS overall parameters are shown (Figure $342 \mathrm{~S} 2 \mathrm{~B})$. The averaged and buffer subtracted 1D scattering curve is shown (Figure 3A).

343 The Guinier analysis of the averaged 1D scattering curve is shown (Figure 3B) and 344 exhibits excellent linearity up to $\mathrm{q} \cdot \mathrm{Rg}<1.3$, the generally accepted upper validity limit of 345 the Guinier approximation for globular proteins. The $\mathrm{Rg}$ value calculated was $32.5 \pm 0.1$ 346 A.The Kratky representation of the scattering data has two characteristic peaks at low 347 angles and approaches the baseline at higher angles $\left(>0.2 \AA^{-1}\right)$, confirming that the 348 protein is well folded (Figure 3C). The distance distribution function curve shows the 

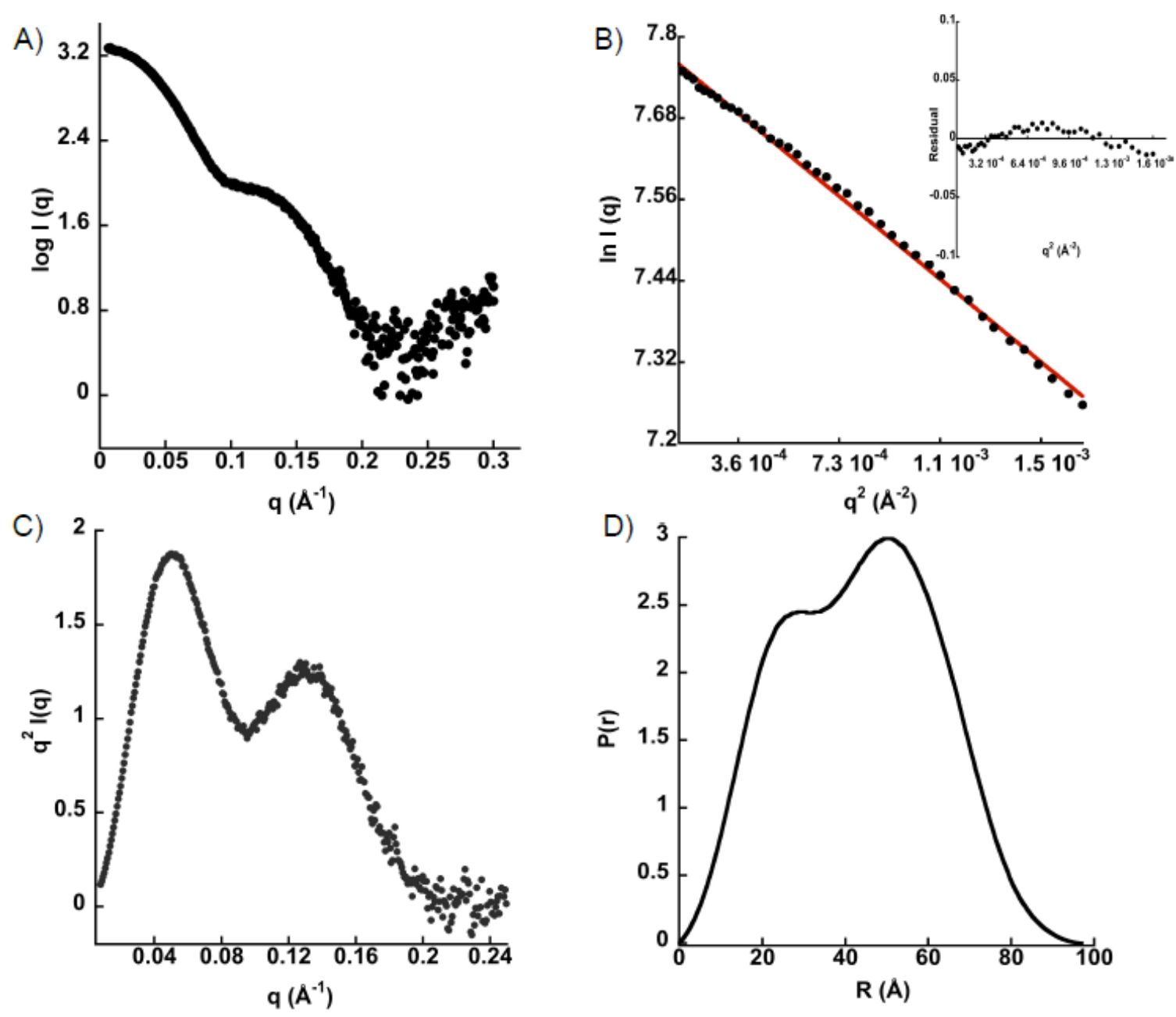

Figure 3: SEC-SAXS of the $\beta$-sliding clamp. A) Buffer subtracted 1D scattering curve. Shown is the average of frames $380-390$ as highlighted in Figure S2. B) Guinier analysis. The $R^{2}$ value for the line was 0.998 . The inset is the residual linear fit in $R_{g} . q$ $<1.3$ region. C) Kratky plot. The plot has a bell shape peak at low momentum transfer (low q) expected of globular macromolecules followed by convergence to $x$-axis. D) The pair wise distance distribution function $p(r)$. The curve shows bell shaped double peak as expected for a ring shaped protein with an inner and outer diameter. The $D_{\max }$ was $95 \AA$.

predicted characteristic double peak in the $p(r)$ curves for a ring-shaped molecule with the $D_{\max }$ value of $97 \AA$ (Figure 3D). A scattering profile calculated from the coordinates for the closed $\beta$ sliding clamp (PDB: 2POL, Kong et al., 1992)) matched the experimental 1D scattering data. The $\chi$ value of the fit was 1.0 and there was good agreement of the experimental $R_{g}$ value of $32.5 \pm 0.1 \AA$ with the calculated value of 33.7 
$\AA$ (Figure 4). To test the possibility that the sliding clamp may exist in an open conformation in solution, an open sliding clamp model was generated. The coordinates

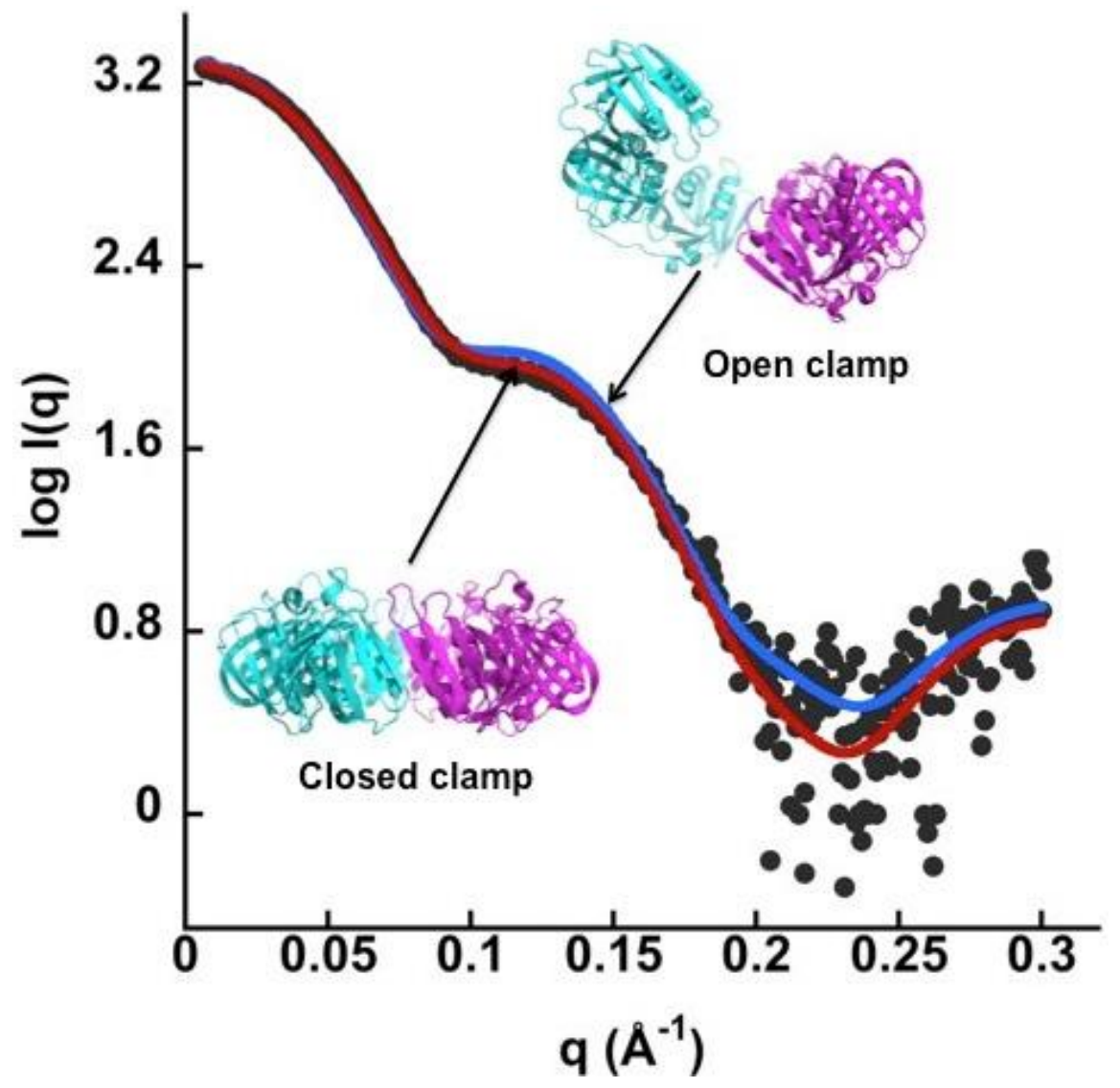

Figure 4: Modeling of the $\beta$-sliding clamp. The program CRYSOL was used for generating 1D scattering profile of the dimeric open and closed $\beta$ clamp. The experimental data is shown in black, the theoretical curve for the closed $\beta$ clamp is shown in red. The $\chi$ of the fit was 1.0 and the cartoon representation of the $\mathrm{X}$-ray crystal structure of the closed clamp is shown (PDB: 2POL). The two monomeric subunits are colored as cyan and magenta. The theoretical curve for the opened clamp with right hand spiral is shown in blue.

of the closed clamp with one monomer rotated about the hinge region of the interface to generate an out of plain opening of $45^{\circ}$. The $\chi$ value for the fit was 5.5 , significantly higher than the $\chi$ value for the fit to the closed clamp. The calculated $R_{g}$ value for the open clamp (34.1 $\AA$ ) did not change significantly in comparison to that for the closed clamp. This data confirmed that the $\beta$ sliding clamp is mainly in a closed dimeric state in 
378 solution where both dimer interfaces are engaged. The closed conformation in solution,

379 in the absence of the clamp loader, was expected because of the long ( 2 hours) half-

380 life of the closed dimeric $\beta$ clamp (Yao et al., 1996). As a result they require the function

381 of the $\gamma$ clamp loader to be loaded onto the primer template junction.

$382 \gamma-\beta$ Complex

383 To obtain a homogeneous solution of the E. coli $\beta$ clamp loader-clamp complex, purified $384 \beta$ sliding clamp and seven subunit $\gamma$ clamp loader were mixed in a 1:1 molar ratio (final 385 concentration of $30 \mu \mathrm{M}$ ) in buffer containing $500 \mu \mathrm{M}$ ATP and $8 \mathrm{mM} \mathrm{MgCl}_{2}$. The $\beta$ clamp 386 loader-clamp complex was then separated from unbound $\beta$ sliding clamp and $\gamma$ clamp 387 loader as well as aggregates immediately prior to data collection using in-line SEC 388 (Figure S3A). The profile demonstrates successful separation of the complex peak as 389 well smaller molecular weight peaks for uncomplexed $\beta$ sliding clamp and $\gamma$ clamp 390 loader. The radius of gyration $\left(R_{g}\right)$, forward scattering intensity $(I(0))$ and I $\left(q_{\min }\right)$ of each 391 exposure frame as well as the chosen frames with consisted $R_{g}$ values for data analysis 392 are shown (Figure S3B). The averaged 1D scattering curve of the $\beta$ clamp loader-clamp 393 complex is shown as the green curve in Figure 5A. The 1D scattering curve of the $\gamma$ 394 clamp loader alone (Figure 1A) is plotted in the same panel to highlight differences 395 between the scattering profiles, which demonstrates the capture of the $\beta$ clamp loader 396 sliding clamp complex. The 1D scattering curve of the complex superimposes well onto 397 the clamp loader 1D scattering profile at low q regions $<0.05$ but shows a significant 398 curvature in q region between $0.075-0.13 \AA^{-1}$ that is absent in the $\gamma$ clamp loader. This 399 curvature corresponds to the presence of the $\beta$ sliding clamp in 

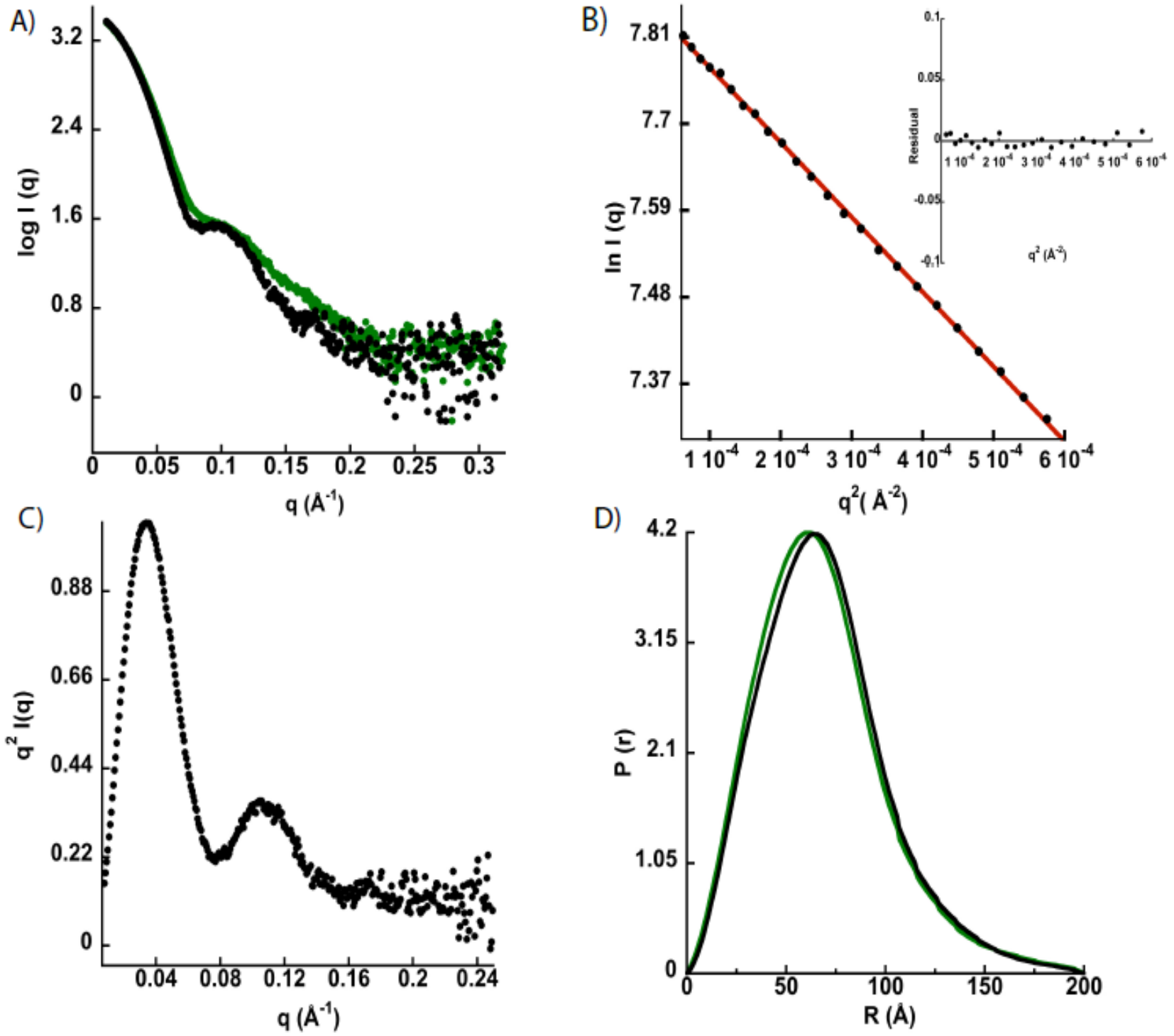

Figure 5: SEC-SAXS of the clamp loader-clamp complex. A) The buffer subtracted 1D scattering curve. Clamp loader-clamp complex (black) and the $\gamma$-clamp loader alone from Figure 1A (green). Shown is the average of frames 340-360 as highlighted in Figure S3. B) Guinier analysis. The $\mathrm{R}^{2}$ value was 0.999 . The inset is the residual linear fit in $\mathrm{R}_{\mathrm{g}} . \mathrm{q}<1.3$ region. C) Kratky plot. The plot has a bell shape peak at low momentum transfer (low q) expected of globular macromolecules followed by convergence to $x$-axis at higher $q$. D) The pair wise distance distribution function $p(r)$. The clamp loader-clamp complex (black) and the clamp loader alone from Figure 1B (green). The curves show bell shaped $p(r)$ functions expected of a protein that is mostly spherical. Both $p(r)$ 411 functions have extended domains corresponding to $\psi \chi \chi$ heterodimeric subunits.

412 the complex. The linearity of the Guinier plot of the clamp loader-clamp complex (Figure $4135 \mathrm{~B}$ ) in the $\mathrm{qR}_{\mathrm{g}}<1.3$ regions is in good agreement with the monodispersity of the 
414 complex sample. The $R_{g}$ value was calculated to be $53.1 \pm 0.2 \AA$. The $R_{g}$ value of the 415 complex is $\sim 2 \AA$ larger than the $\gamma$ clamp loader. This small but significant difference in $416 \quad R_{g}$ values suggests that there is a tight interaction in $\beta$ clamp loader-sliding clamp 417 complex. The Kratky plot shows a typical bell shaped curve at low scattering angles as 418 expected for a globular folded proteins with convergence to the $\mathrm{x}$-axis at higher 419 scattering angles (Figure $5 \mathrm{C}$ ). The $\mathrm{p}(\mathrm{r})$ curve of the complex is similar to that of the $\gamma$ 420 clamp loader with an extended $D_{\max }$ of $200 \AA$ (Figure 5D). But the maximum peak value 421 of the $p(r)$ curve for the complex is shifted to $65.5 \AA$ as compared to the $\gamma$ clamp loader 422 maximum value of $60.0 \AA$ (Figure 1D). As the $\beta$ clamp loader molecular weight is 250 $423 \mathrm{kDa}$ and binding of the sliding clamp increases the size to $330 \mathrm{kDa}$. The difference in $424 p(r)$ curve maxima is expected because of formation of the complex, but the similarity of $425 p(r)$ curves indicate that there is no dramatic change in shape of the $\gamma$ clamp loader 426 once it binds the $\beta$ sliding clamp. The small change in $R_{g}$ value between the $\gamma$ clamp 427 loader and complex is also supportive of this observation.

428 Rigid-body modeling was used to model the conformation of the complex. The atomic 429 structures and their corresponding calculated scattering profiles are shown in Figure 6. 430 The program CRYSOL was used for the generation of calculated scattering profiles of 431 crystal structures. In addition to the differences in scattering profiles for the clamp loader 432 -clamp complex shown in Figure 5A, we were interested in rigid body modeling of the $\beta$ 433 sliding clamp $\gamma$ clamp loader complex SAXS data using previously determined crystal 434 structures. As the differences in $R_{g}$ and the $p(r)$ function for the $\gamma$ clamp loader alone 435 and the complex were relatively small, we wanted to determine whether a scattering 436 profile calculated from the atomic coordinates of the $\gamma$ clamp loader could adequately fit 

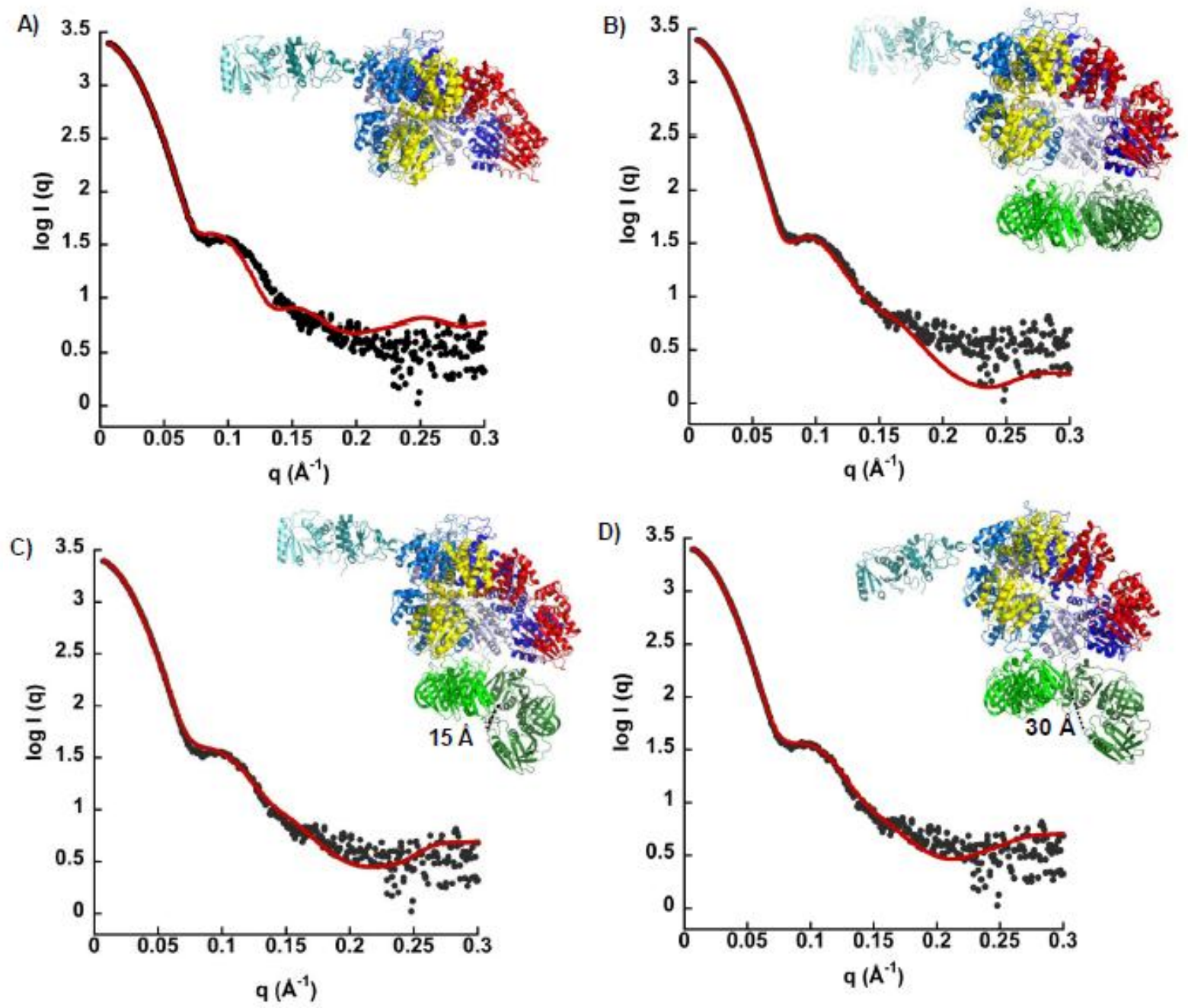

Figure 6: Modeling of the $\gamma-\beta$ clamp loader-clamp complex. The experimental SAXS data is shown in black and the theoretical scattering profiles are shown in red. A) Fitting of the seven subunit clamp loader calculated scattering profile to the experimental data. The color coding of the model is as followed: red $\delta$ subunit, shades of blue $3 \gamma$ subunits, yellow $\delta$ ' subunit and $\chi \psi$ are shown in cyan and teal. B) Fitting of the clamp loaderclosed clamp complex calculated scattering profile to the experimental data. The sliding clamp monomers are presented in light and dark green in the model. The color coding of the models in C and D are the same as in panel B. C) Fitting of the clamp loaderopen clamp calculated scattering profile to the experimental data. The opening of the clamp was modeled by an out of plane movement of one of the monomers about the hinge region so the clamp can have a $15 \AA$ opening at the interface. D) Fitting of the clamp loader-open clamp complex calculated scattering profile to the experimental data. In this model the opening of the clamp at the interface was increased to $30 \AA$.

451 the experimental 1D scattering data for the complex. The calculated scattering profile

452 for the seven-subunit $\gamma$ clamp loader to the experimental data is shown in Figure 6A. 
453 The predicted curve for the $\gamma$ clamp loader alone exhibits discrepancies to the 454 experimental data at various angles. The $\chi$ of fit was 2.0 and the theoretical $R_{g}$ for the 455 model was $48.8 \AA$ compared to the experimental value of $53.1 \pm 0.2 \AA$. Since this fit was 456 not adequate to explain the 1D scatter, an atomic model of the $\beta$ sliding clamp and $\gamma$ 457 clamp loader in a complex was generated (Figure 6B). The model is based on 458 biochemical and structural data that showed the $\mathrm{N}$-terminal domains of the $\beta$ sliding 459 clamp subunits bind to one face of the $\gamma$ clamp loader with the clamp central cavity 460 aligning with the DNA binding channel. The calculated scattering profile of this model 461 showed a much improved fit to the experimental data with a $\chi$ value of 1.3 and a 462 theoretical $R_{g}$ value of $52.8 \AA$.

463 The $\gamma$ clamp loader, once bound to ATP, is able to induce conformational changes onto 464 the $\beta$ sliding clamp at one interface to open its ring structure. Once open, the $\gamma$ clamp 465 loader is loaded onto a primer template junction where the function of the $\beta$ sliding 466 clamp is required either for DNA synthesis or recruitment of various other proteins 467 involved in DNA repair. Given that saturating concentrations of ATP were present in our 468 SAXS samples, in these experiments the clamp loader-clamp complex should exist in 469 an open conformation. One important outstanding question about the mechanism of 470 clamp loading is how far the clamp loader has to open the clamp to place it on DNA.

471 The opening in the clamp interface was only $9 \AA$ in the previously determined T4 clamp 472 loader-clamp-DNA ternary structure. The authors of this study then speculated that the 473 clamp loader threads the clamp on ssDNA with the duplex DNA sliding into the interior 474 chamber of the clamp loader through the central pore of the sliding clamp. The second 
475 speculation was that a fully-opened clamp conformation that would facilitate loading on 476 double-stranded DNA was not captured (Kelch et al., 2011).

477 Hence in this study, the open $\beta$ sliding clamp was modeled to have a right handed spiral 478 to match the geometry of the helical DNA, by an out of plane rotation about one of the 479 interfaces creating a $15 \AA$ opening at the other interface (Figure 6C). This remodeling of 480 an open $\beta$ sliding clamp improved the fit of the calculated scattering profile to the 481 experimental data at higher $q$ regions $(q>0.2)$ compared to the fit of the scattering 482 profile calculated for the closed clamp loader-clamp complex (Figure 6B). Also the 483 calculated $R_{g}$ value of $53.8 \AA$ was in good agreement with the experimental value of $48453.1 \pm 0.2 \AA$, but the $15 \AA$ opening of the clamp is not wide enough for binding duplex 485 DNA. Hence the open $\beta$ sliding clamp model was adjusted with an open interface of 30 $486 \AA$, which is sufficient for binding duplex DNA. The fit of this model calculated scattering 487 profile to the experimental data is shown (Figure 6D) and fits the experimental data 488 better than either the closed clamp loader-clamp complex or the clamp loader-open 489 clamp complex with $15 \AA$ opening at the interface. The $\chi$ value for the fit was 1.1 and 490 there was improved agreement with the experimental data over all $q$ angles. Based on 491 this observation, additional rigid body modeling of the open $\beta$ sliding clamp $\gamma$ clamp 492 loader complex were performed with $\beta$ sliding clamp openings of $10,15,20,25,30$ and $49345 \AA$ at the interface. The $\chi$ value of the fits were $1.8,1.6,1.4,1.2,1.1$ and 1.7 494 respectively, hence the models where the clamp had an opening of 25 or $30 \AA$ fitted the 495 experimental data the best. When the clamp was modeled to have a larger opening of $49645 \AA$, the calculated $R_{g}$ value was also increased to $55.2 \AA$ which is in disagreement 497 with the experimental value of $53.1 \pm 0.2 \AA$. 
498 To answer the question whether the two auxiliary subunits $\chi$ and $\psi$ undergo any 499 movements upon binding of the sliding clamp to the loader, additional modeling of the 500 clamp loader-clamp complex SAXS data were done. For this purpose a clamp loader501 open clamp structural model was generated where the $\chi \psi$ subunits were moved to be 502 positioned closer to the ssDNA exit channel on $\delta$ subunit. The rational for this movement 503 is that the $\chi$ subunit directly interacts with the C-terminal tail of the SSB and therefore 504 expected to be in the vicinity of the ssDNA exit channel once the loader loads the sliding 505 clamp onto primer template DNA. This model is shown in Figure S4. A calculated curve 506 was generated for this model using the program CRYSOL and the curve was fitted onto 507 the experimental scattering profile. The $\chi$ of the fit was at 1.6 and the theoretical $R_{g}$

508 value was decreased to $50.5 \AA$. Although the $\chi$ value of the fit was increased and the $R_{g}$ 509 value was reduces, the movement of $\chi \psi$ subunits cannot be ruled out upon binding of 510 the clamp as the presented model might not be an accurate portrayal of the location of $511 \chi \psi$. But the decrease in radius of gyration for this structural model, as compared to the 512 experimental value, indicates a more extended orientation of $\chi$ and $\psi$.

\section{4. Discussion}

514 In these studies, we have captured for the first time, a solution structure of a prokaryotic 515 clamp loader-sliding clamp complex from E. coli using SAXS-SEC. Prior to these 516 studies, there was no X-ray crystal structure, cryo-EM or SAXS structure of a clamp 517 loader-clamp complex where the clamp had wide enough opening for binding with 518 duplex DNA. An important unanswered question is how does the clamp loader load the 519 clamp onto DNA? If the clamp loader threads the sliding clamp on ssDNA, the clamp 520 loader would only have to open the clamp wide enough to allow ssDNA to pass through 
521 to the center, but would have to displace ssDNA binding protein (SSB). If the clamp

522 loader loads the sliding clamp directly on duplex DNA, the clamp loader has to open the

523 clamp at the interface with opening wide enough to allow duplex DNA to pass through

524 the center of the ring. The SAXS data collected on sliding clamp and the clamp loader

525 individually provided information about the solution structures and conformations of

526 these two essential replication proteins prior to complex formation. The use of SEC-

527 SAXS allowed us to isolate a homogeneous solution of the complex by removing large

528 aggregates and unbound species ensuring higher quality data for a more accurate

529 interpretation and modeling of the clamp loader-clamp complex SAXS data.

530 Rigid body modeling of the seven-subunit clamp loader complex, discussed in Figure 2,

531 was in agreement with the previous results from SAXS studies on the seven subunit $\gamma$

532 clamp loader where the ab initio model of the clamp loader revealed the location of $\chi \psi$

533 subunits located in the vicinity of the $\delta$ ' subunit and away from the ssDNA binding

534 channel on the $\delta$ subunit. Based on these findings a model of interaction of the clamp

535 loader with SSB was previously proposed (Tondnevis et al., 2015). Rigid body modeling

536 of the $\beta$ sliding clamp in solution has revealed that the clamp exists in a closed dimeric

537 conformation under our experimental conditions and in the absence of the clamp loader

538 (Figure 4). This is evident by the close agreement of the calculated scattering profile for

539 the closed clamp to the experimental data as compared to $\chi$ value for the open clamp. It

540 can be concluded that the clamp is quite rigid, keeping its symmetric ring structure. Also

541 looking at the Kratky plot the clamp is well folded and has no large flexible parts to it (no

542 increase or plateau at high q). A solution study of the clamp using hydrogen exchange

543 mass spectroscopy revealed that $\beta$ clamp is not a static closed ring but instead very 
544 dynamic (Fang et al., 2011). Our results are not necessarily contradictory to this 545 dynamic behavior of the clamp as the transient opening that was observed using 546 hydrogen exchange mass spec might not translate into drastic structural changes. It 547 should also be noted that the solution studies by Fang et al were done using lower 548 concentrations of clamp compared to the concentration of the clamp that was used in 549 these SAXS studies. In solution at lower concentration, closer to in vivo concentrations, 550 the sliding clamp appears to be more dynamic. Our observed results, of a close clamp, 551 were also expected because of the several previous single molecule and dynamic 552 simulations studies. Molecular dynamics simulation revealed that $\beta$ has the highest 553 stability in a closed conformation (Jeruzalmi et al., 2001a). The half-life of $\beta$ on a closed 554 circular DNA is roughly 2 hours implying transient opening of $\beta$ leading to its dissociation 555 from DNA is infrequent (Yao et al., 1996). The requirement of a clamp loader for binding 556 and opening of the clamp and its assembly onto the primer template junction is also in 557 support of the sliding clamp existing in a closed dimeric conformation prior to interaction 558 with the clamp loader.

559 Binding of ATP to the clamp loader, primes the macromolecule for binding and opening 560 of the clamp (Berdis and Benkovic, 1996; Burgers, 1991; Hingorani and O'Donnell, 561 1998; Naktinis et al., 1995; Tsurimoto and Stillman, 1991; Turner et al., 1999). In our 562 rigid body modeling of the clamp loader-clamp complex, we modeled the sliding clamp 563 to be in closed and open conformations as shown (Figure 6). The rigid body modeling of 564 the $\gamma-\beta$ clamp loader clamp complex with the closed and open siding clamp suggests 565 that the sliding clamp is opened once bound to the clamp loader in readiness for binding 566 the duplex DNA. The model of the clamp loader-open clamp complex, where the clamp 
567 was modeled to have a wide enough opening of $30 \AA$ at the interface, exhibits the least discrepancy and close agreement with the experimental data. Further opening of the clamp resulted in $R_{g}$ values that were too large and in disagreement of the experimental 570 value for the clamp loader-clamp complex. The $25-30 \AA$ opening is wide enough for 571 loading of the clamp onto the duplex DNA as compared to the opening of the clamp in

572 complex with the clamp loader from bacteriophage T4 and the archaeal RFC-PCNA 573 complex structures where the clamps had opening of $9 \AA$ and $5 \AA$ opening respectively.

574 The similarity of the overall clamp loader-clamp interaction in E. coli as compared to the 575 eukaryotic, archaeal and bacteriophage clamp loader clamp interaction highlights the 576 importance and conservation of this essential protein-protein interaction in all domains 577 of life. It would be of great advantage to perform time resolved (TR-SAXS) studies to 578 examine if the opening of the clamp could be visualized in real time in the future. It 579 would also be advantages to perform SAXS studies using clamp loader that is 580 comprised of three $\tau$ subunits as the main focus of this body of work was on the clamp

581 loader comprised of three $\gamma$ subunits. There is the possibility that the $\tau$ subunits would 582 induce additional conformational changes on the clamp loader as well as the sliding 583 clamp and repetition of these studies with the clamp loader containing $\tau$ subunits would 584 be informative.

\section{Acknowledgements}

586 Use of the Stanford Synchrotron Radiation Lightsource, SLAC National Accelerator 587 Laboratory, is supported by the U.S. Department of Energy, Office of Science and 588 Office of Basic Energy Sciences under Contract No. DE-AC02-76SF00515. The SSRL 589 Structural Molecular Biology Program is supported by the DOE Office of Biological and 590 Environmental Research, and by the National Institutes of Health, National Institute of 591 General Medical Sciences (including P41GM103393). The contents of this publication 592 are solely the responsibility of the authors and do not necessarily represent the official 
593 views of NIGMS or NIH. This work was also funded by the NIH T32 training grant No. 594 2T32AI007110-31A1. 


\section{References}

Alley, S.C., Shier, V.K., Abel-Santos, E., Sexton, D.J., Soumillion, P., and Benkovic, S.J. (1999). Sliding clamp of the bacteriophage T4 polymerase has open and closed subunit interfaces in solution. Biochemistry 38, 7696-7709.

Anderson, S.G., Thompson, J.A., Paschall, C.O., O'Donnell, M., and Bloom, L.B. (2009). Temporal correlation of DNA binding, ATP hydrolysis, and clamp release in the clamp loading reaction catalyzed by the Escherichia coli gamma complex. Biochemistry 48, 8516-8527.

Benkovic, S.J., Valentine, A.M., and Salinas, F. (2001). Replisome-mediated DNA replication. Annu. Rev. Biochem. 70, 181-208.

Berdis, A.J., and Benkovic, S.J. (1996). Role of adenosine 5'-triphosphate hydrolysis in the assembly of the bacteriophage T4 DNA replication holoenzyme complex. Biochemistry 35, 9253-9265.

Bowman, G.D., O'Donnell, M., and Kuriyan, J. (2004). Structural analysis of a eukaryotic sliding DNA clamp-clamp loader complex. Nature 429, 724-730.

Burgers, P.M. (1991). Saccharomyces cerevisiae replication factor C. II. Formation and activity of complexes with the proliferating cell nuclear antigen and with DNA polymerases delta and epsilon. J. Biol. Chem. 266, 22698-22706.

Emsley, P., and Cowtan, K. (2004). Coot: model-building tools for molecular graphics. Acta Crystallogr. D Biol. Crystallogr. 60, 2126-2132.

Erzberger, J.P., and Berger, J.M. (2006). Evolutionary relationships and structural mechanisms of AAA+ proteins. Annu Rev Biophys Biomol Struct 35, 93-114.

Fang, J., Engen, J.R., and Beuning P.J. (2011). Escherichia coli processivity clamp beta from DNA polymerase III is dynamic in solution. Biochemistry 50, 5958-5968

Gao, D., McHenry, C.S. (2001). Tau binds and organizes Escherichia coli replication proteins through distinct domains. Domain III, shared by gamma and tau, binds delta delta ' and chi psi. J Biol Chem. 276, 4447-4453

Gill SC, von Hippel PH. (1989). Calculation of protein extinction coefficients from amino acid sequence data. Anal. Biochem. 182, 319-326.

Glover, B.P., and McHenry, C.S. (1998). The chi psi subunits of DNA polymerase III holoenzyme bind to single-stranded DNA-binding protein (SSB) and facilitate replication of an SSB-coated template. J. Biol. Chem. 273, 23476-23484.

Gulbis, J.M., Kazmirski, S.L., Finkelstein, J., Kelman, Z., O'Donnell, M., and Kuriyan, J. (2004). Crystal structure of the chi:psi sub-assembly of the Escherichia coli DNA polymerase clamploader complex. Eur. J. Biochem. 271, 439-449.

Hingorani, M.M., and O'Donnell, M. (1998). ATP binding to the Escherichia coli clamp loader powers opening of the ring-shaped clamp of DNA polymerase III holoenzyme. J. Biol. Chem. 273, 24550-24563. 
Huang, T.C., Toraya, H., Blanton, T.N., And Wu, Y. (1993). X-Ray-Powder Diffraction Analysis of Silver Behenate, a Possible Low-Angle Diffraction Standard. J Appl Crystallogr. 26, 180-184.

Jarvis, T.C., Paul, L.S., Hockensmith, J.W., and Hippel, von, P.H. (1989). Structural and enzymatic studies of the T4 DNA replication system. II. ATPase properties of the polymerase accessory protein complex. J. Biol. Chem. 264, 12717-12729.

Jeruzalmi, D., Yurieva, O., Zhao, Y., Young, M., Stewart, J., Hingorani, M., O'Donnell, M., and Kuriyan, J. (2001a). Mechanism of processivity clamp opening by the delta subunit wrench of the clamp loader complex of E. coli DNA polymerase III. Cell 106, 417-428.

Jeruzalmi, D., O'Donnell, M., and Kuriyan, J. (2001b). Crystal Structure of the Processivity Clamp Loader Gamma $(\gamma)$ Complex of E. coli DNA Polymerase III. Cell 106, 429-441.

Johanson, K.O., Haynes, T.E., and McHenry, C.S. (1986). Chemical characterization and purification of the beta subunit of the DNA polymerase III holoenzyme from an overproducing strain. J. Biol. Chem. 261, 11460-11465.

Kazmirski, S.L., Podobnik, M., Weitze, T.F., O'Donnell, M., and Kuriyan, J. (2004). Structural analysis of the inactive state of the Escherichia coli DNA polymerase clamp-loader complex. Proc. Natl. Acad. Sci. U.S.a. 101, 16750-16755.

Kelch, B.A., Makino, D.L., O'Donnell, M., and Kuriyan, J. (2011). How a DNA polymerase clamp loader opens a sliding clamp. Science 334, 1675-1680.

Konarev, P.V., Volkov, V.V., Sokolova, A.V., Koch, M.H.J., and Svergun, D.I. (2003). PRIMUS: a Windows PC-based system for small-angle scattering data analysis. J Appl Crystallogr 36, 1277-1282.

Kong, X.P., Onrust, R., O'Donnell, M., and Kuriyan, J. (1992). Three-dimensional structure of the beta subunit of E. coli DNA polymerase III holoenzyme: a sliding DNA clamp. Cell 69, 425437.

Martel, A., Liu, P., Weiss, T.M., Niebuhr, M., and Tsuruta, H. (2012). An integrated highthroughput data acquisition system for biological solution X-ray scattering studies. J Synchrotron Radiat 19, 431-434.

Mclnerney, P., Johnson. A., Katz, F., O'Donnell, M. (2007). Characterization of a Triple DNA Polymerase Replisome. Mol Cell 27, 5287-538.

McPhillips, T.M., McPhillips, S.E., Chiu, H.J., Cohen, A.E., Deacon, A.M., Ellis, P.J., Garman, E., Gonzalez, A., Sauter, N.K., Phizackerley, R.P., et al. (2002). Blu-lce and the Distributed Control System: software for data acquisition and instrument control at macromolecular crystallography beamlines. J Synchrotron Radiat 9, 401-406.

Millar, D., Trakselis, M.A., and Benkovic, S.J. (2004). On the solution structure of the T4 sliding clamp (gp45). Biochemistry 43, 12723-12727.

Miyata T, Suzuki H, Oyama T, Mayanagi K, Ishino Y, Morikawa K. (2005) Open clamp structure in the clamp-loading complex visualized by electron microscopic image analysis. Proc Natl Acad Sci (USA) 102:13795-13800 
Moolman, M.C., Krishnan, S.T., Kerssemakers, J.W.J., van den Berg, A., Tulinski, P., Depken, M., Reyes-Lamothe, R., Sherratt, D.J., and Dekker, N.H. (2014). Slow unloading leads to DNAbound $\beta 2$-sliding clamp accumulation in live Escherichia coli cells. Nat Commun 5, 5820.

Naktinis, V., Onrust, R., Fang, L., and O'Donnell, M. (1995). Assembly of a chromosomal replication machine: two DNA polymerases, a clamp loader, and sliding clamps in one holoenzyme particle. II. Intermediate complex between the clamp loader and its clamp. J. Biol. Chem. 270, 13358-13365.

Neuwald, A.F., Aravind, L., Spouge, J.L., and Koonin, E.V. (1999). AAA(+): A class of chaperone-like ATPases associated with the assembly, operation, and disassembly of protein complexes. Genome Res. 9, 27-43.

Olson, M.W., Dallmann, H.G., McHenry, C.S.(1995) DnaX complex of Escherichia coli DNA polymerase III holoenzyme. The chi psi complex functions by increasing the affinity of tau and gamma for delta.delta' to a physiologically relevant range. J Biol Chem, 270, 29570-29577.

Onrust, R., Stukenberg, P.T., and O'Donnell, M. (1991). Analysis of the ATPase subassembly which initiates processive DNA synthesis by DNA polymerase III holoenzyme. J. Biol. Chem. 266, 21681-21686.

Pettersen, E.F., Goddard, T.D., Huang, C.C., Couch, G.S., Greenblatt, D.M., Meng, E.C., and Ferrin, T.E. (2004). UCSF Chimera--a visualization system for exploratory research and analysis. J Comput Chem 25, 1605-1612.

Pomerantz, R.T., and O'Donnell, M. (2007). Replisome mechanics: insights into a twin DNA polymerase machine. Trends Microbiol. 15, 156-164.

Rambo, R.P., and Tainer, J.A. (2011). Characterizing Flexible and Intrinsically Unstructured Biological Macromolecules by SAS Using the Porod-Debye Law. Biopolymers 95, 559-571.

Shamoo, Y., and Steitz, T.A. (1999). Building a replisome from interacting pieces: sliding clamp complexed to a peptide from DNA polymerase and a polymerase editing complex. Cell 99, 155166.

Simonetta, K.R., Kazmirski, S.L., Goedken, E.R., Cantor, A.J., Kelch, B.A., McNally, R., Seyedin, S.N., Makino, D.L., O'Donnell, M., and Kuriyan, J. (2009). The mechanism of ATPdependent primer-template recognition by a clamp loader complex. Cell 137, 659-671.

Smolsky, I.L., Liu, P., Niebuhr, M., Ito, K., Weiss, T.M., and Tsuruta, H. (2007). Biological smallangle $\mathrm{x}$-ray scattering facility at the Stanford synchrotron radiation laboratory. J Appl Crystallogr 40, S453-S458.

Stukenberg, P.T., Studwell-Vaughan, P.S., and O'Donnell, M. (1991). Mechanism of the sliding beta-clamp of DNA polymerase III holoenzyme. J. Biol. Chem. 266, 11328-11334.

Svergun, D.I. (1992). Determination of the Regularization Parameter in Indirect-Transform Methods Using Perceptual Criteria. J Appl Crystallogr 25, 495-503.

Svergun, D., Barberato, C., and Koch, M. (1995). CRYSOL-a program to evaluate X-ray solution scattering of biological macromolecules from atomic coordinates. J Appl Crystallogr. 28, 768- 
773.

709 Tondnevis, F., Gillilan, R.E., Bloom L.B,. and McKenna, R. (2015). Solution study of the 710 Escherichia coli DNA polymerase III clamp loader reveals the location of the dynamic $\Psi \mathrm{X}$ 711 heterodimer. Structural Dynamics. 2. 054701.

712 Tsurimoto, T., and Stillman, B. (1991). Replication factors required for SV40 DNA replication in 713 vitro. I. DNA structure-specific recognition of a primer-template junction by eukaryotic DNA

714 polymerases and their accessory proteins. J. Biol. Chem. 266, 1950-1960.

715 Turner, J., Hingorani, M.M., Kelman, Z., and O'Donnell, M. (1999). The internal workings of a 716 DNA polymerase clamp-loading machine. Embo J. 18, 771-783.

717 Wu CA, Zechner EL, Hughes AJ, Jr, Franden MA, McHenry CS, Marians KJ. (1992)

718 Coordinated leading- and lagging-strand synthesis at the Escherichia coli DNA replication fork.

719 IV. Reconstitution of an asymmetric, dimeric DNA polymerase III holoenzyme. J Biol Chem.

$720 \quad 267: 4064-4073$.

721 Yao, N., Turner, J., Kelman, Z., Stukenberg, P.T., Dean, F., Shechter, D., Pan, Z.Q., Hurwitz, J., 722 and O'Donnell, M. (1996). Clamp loading, unloading and intrinsic stability of the PCNA, beta and 723 gp45 sliding clamps of human, E. coli and T4 replicases. Genes Cells 1, 101-113. 